\title{
Elimination of the effect of progressive collapse as a factor in increasing the environmental friendliness of district buildings
}

\author{
Ruslan Taroev ${ }^{1 *}$, Alexandr Makovckin ${ }^{1}$, Denis Shcheglov ${ }^{1}$, Radion Rogulin ${ }^{1,2}$, and Valery \\ Abbakumov ${ }^{1}$ \\ ${ }^{1}$ Far Eastern Federal University, Applied mathematics, mechanics, controlling and software, \\ Sukhanova, 8, Vladivostok 690922, Russia \\ ${ }^{2}$ Vladivostok state unviersity of economics and service, mathematics and modelling, Gogolya, 41, \\ Vladivostok, 690014, Russia
}

\begin{abstract}
The work is devoted to the principle of designing residential quarters with the exclusion of building collapse according to the "domino" principle, ie. without the development of progressive collapse in the event of an accident. This principle increases the efficiency of the "green" development of the construction industry. The work provides real examples when the mistake of the architect of the improvement of the district cost the integrity of a large quarter, presents pictures of man-made disasters associated with the collapse of entire microdistricts. The text of the article is a study of methods and tools for designing buildings and structures, which, being combined into one quarter, will be able to maintain structural integrity in the event of a collapse of one of the components of such a residential building. The principles of calculating a reinforced concrete monolith that prevent progressive collapse are highlighted. Also, the text of the article contains the author's nomogram, obtained empirically and confirmed by experiments.
\end{abstract}

\section{Introduction}

Buildings and structures must be protected from all types of force effects, including from the action of special loads and emergency loads. Measures to protect construction objects are determined when designing their load-bearing structural elements, depending on the degree of responsibility of the building or structure.

In any case, the design should provide for the protection of the construction object from the progressive (chain) collapse of structures by calculation and structural technical solutions.

The last requirement means that for any force impact, including not provided for by the project (emergency), the structural system of a building or structure must ensure its strength and stability in the event of local destruction of load-bearing structures at least for the time required for the evacuation of people. The movement of structures and the opening of cracks in them in the emergency situation under consideration is not limited.

\footnotetext{
* Corresponding author: nauka.teo@mail.ru
} 
The progressive collapse of structures of buildings and structures occurs mainly from a sudden change in the structural scheme adopted in the design due to the destruction of individual parts or load-bearing elements from an emergency impact (explosion, seismic shock, shock wave, mechanical shock of an aircraft, fire, etc.), as well as when they are damaged as a result of soil subsidence, reconstruction, redevelopment, local local loading.

The main reason, with the exception of the human factor, of progressive collapse is design flaws caused by the absence or imperfection of the design and design prerequisites of the regulatory framework to prevent or reduce the catastrophic consequences of this phenomenon [1-5].

Taking into account the possible significant increase in the cost of construction in the case of design taking into account the prevention of progressive collapse, it should be provided for its complete exclusion only in an exclusive manner, for the most critical construction objects, the sudden destruction of which can cause the death of a significant number of people or irreversible man-made and natural catastrophic consequences.

In other cases, it is necessary to strive when designing to meet the basic design requirements that significantly reduce the risk of progressive collapse of structures during their operation.

Over the past decades, the problem of safety of buildings and structures made of reinforced concrete has become aggravated (Fig. 1). The alarming recurrence and analysis of the causes of the catastrophic progressive destruction of the bearing parts of buildings after the completion of construction shows that the design solutions adopted on the basis of modern regulatory requirements are not sufficiently reliable and require reassessment.

The most urgent problem of the safety of buildings and structures made of reinforced concrete becomes in the case of exposure to special loads of a dynamic nature, at which force values that exceed those provided by the static calculation can be achieved, and then the danger of progressive collapse increases significantly.

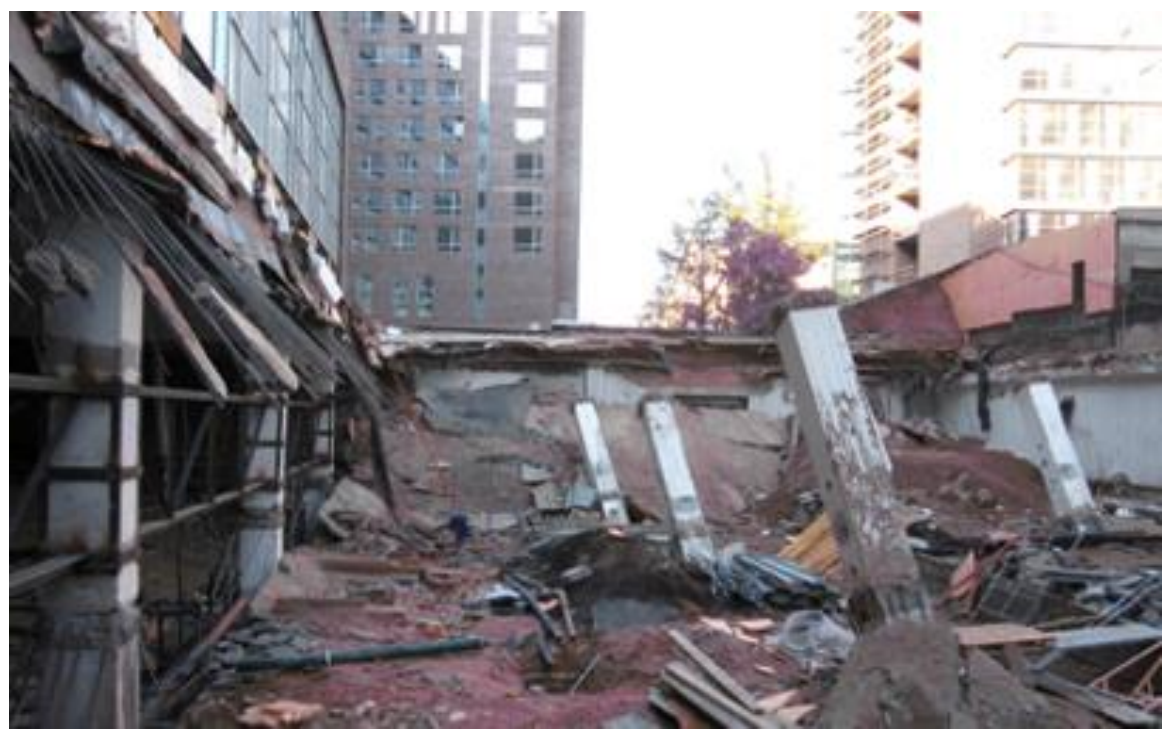

Fig. 1. Accident with successive collapse

\section{Material and methods}

Designs of buildings in order to protect them from progressive collapse should provide for technical solutions of structures and their nodal connections with a sufficient ability to 
dissipate energy while maintaining the overall resistance of buildings to the action of horizontal and vertical loads, even when the structural scheme of their individual parts is changed [6-7].

To ensure the stability of monolithic reinforced concrete buildings against progressive collapse during static and short-term dynamic loading, it is advisable to use in the design:

- rational structural and planning solutions of buildings, taking into account the possibility of the emergence of the emergency situation under consideration;

- constructive measures that ensure the continuity of structures and a sufficient ability to dissipate (dissipate) energy without significantly reducing their overall resistance to static and short-term dynamic loads [8];

- application of design prerequisites and methods that provide for the possibility of deep plastic deformation of design sections without brittle fracture in concrete in order to redistribute efforts in statically indeterminate structural systems and reduce the dynamism coefficient;

- the use of reinforcing bars with a profile and mechanical properties that ensure the effectiveness of joint work with concrete (compressive stability, strength, deformability and energy intensity of adhesion to concrete during plastic deformation during tension), to facilitate the development of plastic deformations in structural elements and their joints at an extreme stage deformation of design sections;

- reserves of the bearing capacity of bending elements, including by taking into account the influence of thrust forces from the surrounding structures, plastic deformation of elements and their design sections to reduce the effect of dynamism under loading, the use of reinforcement and concrete of increased strength, etc.

The possibility of redistribution of efforts in statically indeterminate structural systems of monolithic reinforced concrete buildings, ensuring their adaptability to various types of external force effects (survivability), is determined by the ability to plastic deformation of the most loaded sections and nodal connections of elements, which becomes possible when their brittle destruction on concrete is excluded.

Reinforcement of reinforced concrete structures of monolithic buildings largely determines their resistance against progressive collapse, as it ensures the continuity of structures and the possibility of redistribution of efforts due to plastic deformation of the metal.

The most dangerous from the point of view of progressive collapse are the places of butt joints of reinforcement and its anchoring in concrete.

Thus, when designing sections of reinforced concrete elements, taking into account shortterm dynamic loads, it is recommended to focus on the values $\xi$ max.d $\leq 0.25$, which is consistent with the Euro recommendations for structures whose ductility deformation can be considered satisfactory without special verification.

Recommended prerequisites for calculating reinforced concrete structures in order to prevent progressive collapse, provide for deep plastic deformation of their design sections.

This, in turn, should be accompanied by a high reliability of the anchoring of the reinforcement in the places of its rupture or joining, especially in the supporting and span sections, that is, where the maximum bending moments or shear forces.

The most reliable is the method of continuous reinforcement of reinforced concrete statically indeterminate elements (beams, slabs), which is ensured both by welding rods along the length and by using long reinforcement bars.

Figure 2 shows the author's nomogram of the characteristics of reinforced concrete

It is known that the bearing capacity of reinforced concrete bending elements operating with a thrust created as a result of their interaction with the surrounding structures, under static and short-term dynamic loads, can be significantly higher than the bearing capacity of elements operating without thrust. 


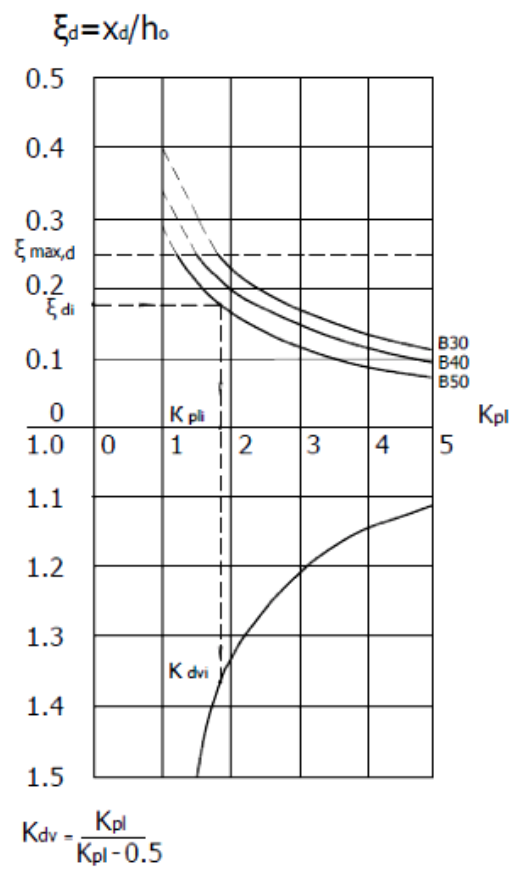

Fig. 2. Accident with successive collapse

The strength and ability to plastic deformation of the design sections of reinforced concrete elements of buildings largely depend on the mechanical properties of the reinforcement used in the design, the effectiveness of adhesion to concrete of its surface.

It has been established that the efficiency of using reinforcement with increased strength in compressed elements depends on the deformative characteristics of concrete under compression [9-11]. When the ultimate deformations of concrete in compression are greater than the deformations of the reinforcement, corresponding to the achievement of stresses equal to the physical or conventional yield strength, premature destruction of concrete from tensile forces caused by the loss of stability of compressed rods can occur.

With the usual transverse reinforcement of centrally compressed elements, due to the above reason, an increase in the strength of the reinforcement above the A500 class is impractical.

At the same time, in the centrally compressed and in the compressed zone of bending elements during static and dynamic fracture, due to the higher deformative characteristics of compressed concrete, the expediency of using reinforcement of class A600 appears.

When using indirect transverse reinforcement in the form of reinforcing meshes or spiral reinforcement, as well as in the case of using fiber-reinforced concrete, the ultimate deformations of concrete during compression increase significantly. This will make it possible to effectively use high-strength reinforcement class A800, which will significantly increase the bearing capacity of compressed elements of buildings. Figures 3 and 4 show examples of the start of deformation of the building foundation.

It has been established that the use of high-strength reinforcement in non-stressed bending reinforced concrete elements due to the tightening of the requirements of SNiP 52-011-2003 to the calculation of the crack opening width is limited to class A400 [2]. Research Center for Design and Expertise of NIIZhB them. A.A. Gvozdev showed the possibility of effective use of A500 class reinforcement with a four-sided sickle-shaped surface profile (A500SP) 
not only to increase the crack resistance of reinforced concrete structures, but also to ensure high operational reliability of the sections of reinforcement bars anchored in concrete [3].

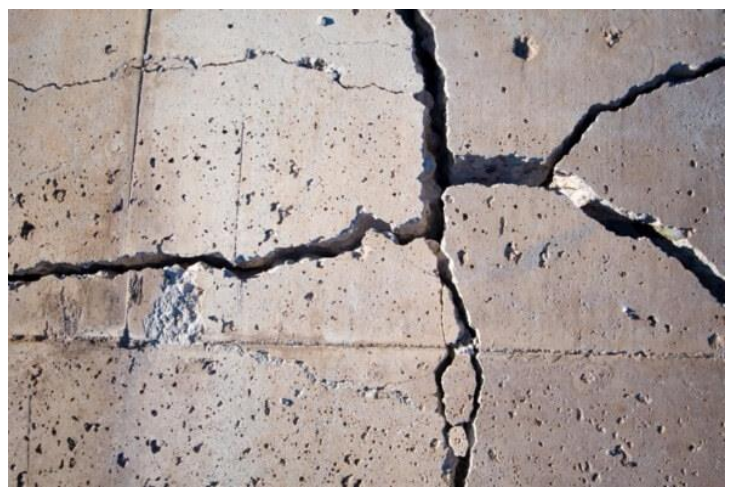

Fig. 3. Deformation of concrete along the length of the reinforcing bars.

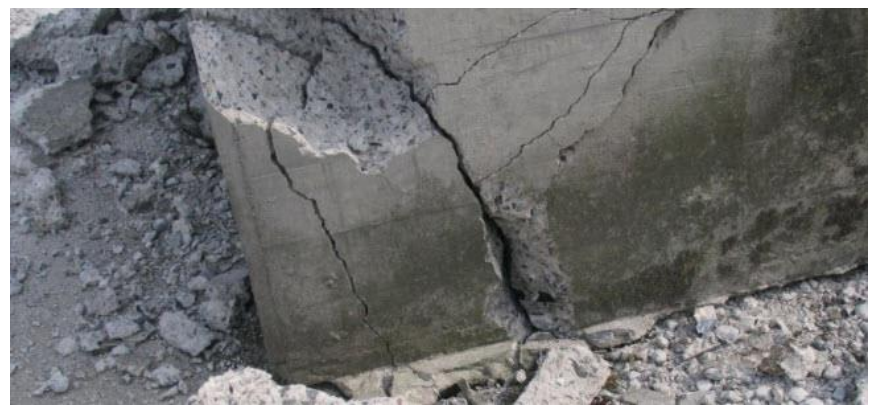

Fig. 4. Deformation of concrete by shear leading to slipping of the building.

The advantages of A500SP class reinforcement over European reinforcement are most pronounced when analyzing the deformation of anchoring end sections after reaching the yield point in it. The energy intensity of the destruction of the adhesion of the A500SP reinforcement when pulling its unloaded end from the concrete prisms is more than 3 times higher than the energy consumption of the destruction of the adhesion of the reinforcement with the profile of the European type.

A higher anchoring capacity of A500SP class reinforcement in comparison with A500C was also established by comparative tests of reinforced concrete beams with fracture along an inclined section.

Based on the results of tests carried out on the basis of the FEFU laboratory, let's say:

- the length of anchoring inserted beyond the point of application of the shear force or the reaction of the support, the amount of transverse reinforcement in these zones and the effectiveness of adhesion to concrete of the profile of the surface of the longitudinal reinforcement actively affect the value of the resistance of the rods that are cut off in the zone of action of the transverse forces and are driven behind the support;

- the beginning of the process of displacement of the ends of the bars of reinforcement of the A500SP class occurred at significantly higher loads than the reinforcement of the A500C class. At the same time, the displacement values with increasing load up to its maximum value at each stage of loading were 1.5-2 times less for A500SP class reinforcement than for A500S reinforcement;

In the presence of transverse reinforcement behind the support, the load corresponding to the beginning of displacement in the серииV series of beams of the ends of reinforcement of class A500CП exceeded the similar load for specimens with A500C more than three times. 
In series IIIa beams, where there was no transverse reinforcement, this excess was only 1.2 times

The advantage of A500SP class fittings is obvious. The characteristic "fir-tree" arrangement of cracks on the lower surface of the beams in the zone of the end sections of the middle rods of the a series cut off in the span indicates the presence of significant splitting forces here, even with sufficiently strong transverse reinforcement.

Longitudinal and oblique cracks formed at the limiting stage facilitate the release of the end sections of the broken rods from concrete and significantly reduce their share in the total resistance of longitudinal reinforcement in an inclined section.

Execution at NIIZhB them. AA Gvozdev's research allowed recommending A500SP class reinforcement for wide use in reinforced concrete structures, including those used in domestic buildings and structures designed to prevent progressive collapse and during construction in earthquake-prone areas [4-6].

This innovative domestic development is protected by domestic and 8 foreign patents. With its application, more than 20 types of series of typical design documentation have been revised and introduced, which made it possible to save up to $28 \%$ of reinforcement in reinforced concrete structures. The A500SP class fittings are widely used at construction sites in the CIS countries and the countries of the near and far east.

Based on the analysis of data from extensive experimental and theoretical studies of both the properties of various types of reinforcement and the work of reinforced concrete elements, under static and short-term dynamic loading carried out by the N.I. A.A. Gvozdev, a systemic set of recommendations has been developed regarding the principles of designing reinforcement to prevent progressive collapse, which is advisable to adhere to in the modern design practice of monolithic housing construction.

The publication format allows you to state the fundamental provisions of the recommendations and the data supporting them. A more detailed presentation of these materials can be found in the attached list of cited sources. Some of them were taken into account in the development of regulatory and recommendatory documents [4-6].

\section{Discussions}

1. Safety of buildings and structures made of reinforced concrete under the influence of all types of emergency loads is determined by the efficiency of reinforcement of sections of structural elements and the possibility of their plastic deformation, determined by the properties of the types of reinforcement selected in the design, calculation methods and design principles [12-14].

2. Based on the analysis of data from studies of the strength and ductility of adhesion to concrete of reinforcement with different profile configurations, a new type of profile with a four-sided arrangement of crescent-shaped transverse ribs has been developed, which makes it possible to achieve indicators that determine a higher adhesion strength (in comparison with a sickle-shaped double-sided "euro profile") and not inferior to those of reinforcement with an annular profile in accordance with GOST 5781. At the same time, very important for preventing progressive destruction, the indicator of the reinforcement of this profile (energy capacity of adhesion resistance) is significantly higher than that of both mentioned profile configurations [3, 9-10]. The new profile was adopted by the largest valve manufacturer Evraz-United ZSMK OJSC (Novokuznetsk) for the mass production of A500SP class valves. For 6 years, more than 1.5 million tons of fittings of this class have been produced and used.

(3) The advantages of reinforcing bent reinforced concrete elements with A500SP grade steel in terms of crack resistance and deformability have been experimentally demonstrated. The excess of the experimental average relative deformations of tensile reinforcement and deflections at breaking load over their values when the yield strength in reinforcement was 
reached in beams with $\xi \approx 0.08$ with reinforcement of the A500SP class ( $\left.\mathrm{f} \_\mathrm{R}=0.075\right)$ were significantly higher than in beams with reinforcement of the A500C class ( $\mathrm{f} R=0.057)$.

This indicates the effectiveness of using reinforcement with a new profile when it is necessary to redistribute the forces in statically indeterminate bending elements at high values of relative deformations and stresses in the working reinforcement, and, consequently, the real possibility of increasing the plasticity coefficient (K_dv) of normal sections [9].

4. The performed studies have confirmed the high residual bearing capacity, deformability and crack resistance is weak reinforced beams after short-term loading with the achievement of large plastic and elastoplastic deformations $\left(K \_p l \approx 3\right)$ in reinforcement of classes A500, A600 and A800. Comparison of the areas of hysteresis loops of deformation of reinforcement of classes A500C and A500SP clearly indicate the advantages of the latter, which has improved characteristics of adhesion to concrete [13-15].

5. The use of reinforcing steel of the A500SP class instead of A500C in bent reinforced concrete elements allows for more effective resistance of their inclined sections to the action of shear forces, especially when the bending moment is dominant.

6 . When designing bending reinforced concrete elements, taking into account the possible impact of emergency dynamic loads, the relative height of the compressed zone of concrete $\xi \_\max \leq 0.25$ should be taken to ensure the possibility of redistribution of efforts.

\section{Conclusions}

In conclusion, it should be said that in our time the degree of responsibility for an entire area is much lower than for a single building within such a unit. This should be given more attention, increasing the responsibility of architects and designers to the level of collective responsibility for the entire area.

\section{References}

1. S. Panahia, S.M. Zahrai, Structures, 31, 1163-1172 (2021)

2. Y. Tiana, K. Lin, Journal of Building Engineering, 41, 102790 (2021)

3. M. Ehaba, H. Salemb, Case Studies in Construction Materials, 13, e00457 (2020)

4. A.M. Yousef, M.A. El-Mandouh, Case Studies in Construction Materials, 13, e00470 (2020)

5. Y. Tiana, K. Linb, X. Lua, Soil Dynamics and Earthquake Engineering, 139, 106370 (2020)

6. H. Shakib, M. Zakersalehi, V. Jahangiri, R. Zamanian, Structures, 28, 205-224 (2020)

7. Q. Zhang, Y.-G. Zhao, K. Kolozvari, L. Xu, Structures, 215, 110688 (2020)

8. I.M.H. Alshaikh, B.H. Abu Bakar, E.A.H. Alwesabi, H.Md Akil, Structures, 25, 881$900(2020)$

9. S. Nyunn, F. Wang, J. Yang, Q.-f. Liu, I. Azim, S. Bhatta, Structures, 28, 1050-1059 (2020)

10. L-m. Tian, Q.-b. Li, W.-h. Zhong, J.-p. Wei, Engineering Failure Analysis, 106, 104158 (2019)

11. H. Tang, X. Deng, Y. Jia, J. Xiong, Ch. Peng, Engineering Structures, 199, 109618 (2019)

12. S. Shan, Sh. Li, Sh. Wang, Journal of Constructional Steel Research, 162, 105720 (2019) 
13. X. Lu, L. Zhang, K. Lin, Y. Li, Engineering Structures, 186, 227-242 (2019)

14. Q. Han, X. Li, M. Liu, B.F. Spencer, Thin-Walled Structures, 140, 404-415 (2019)

15. M-H. Tsai, Z-K. You, Mechanics Research Communications, 40, 56-62 (2012) 